\title{
Global childhood cancer survival estimates and priority-setting - a simulation-based analysis
}

\author{
Zachary J. Ward ${ }^{1 *}, \mathrm{MPH}$, Jennifer M. Yeh ${ }^{2,3+}, \mathrm{PhD}$, Nickhill Bhakta ${ }^{4}, \mathrm{MD}, \mathrm{A}$. Lindsay \\ Frazier, ${ }^{5} \mathrm{MD}$, Fabio Girardi, ${ }^{6} \mathrm{MD}$, Prof Rifat Atun ${ }^{7,8+}$, FRCP
}

1. Center for Health Decision Science, Harvard T.H. Chan School of Public Health, Harvard University, Boston, MA, USA

2. Division of General Pediatrics, Boston Children's Hospital, Boston, MA, USA

3. Department of Pediatrics, Harvard Medical School, Harvard University, Boston, MA, USA

4. Department of Global Pediatric Medicine, St Jude Children's Research Hospital, Memphis, TN, USA

5. Dana-Farber/Boston Children's Cancer and Blood Disorders Center, Boston, MA, USA

6. Cancer Survival Group, Department of Non-communicable Disease Epidemiology, London School of Hygiene and Tropical Medicine, London, UK

7. Department of Global Health and Population, Harvard T.H. Chan School of Public Health, Harvard University, Boston, MA, USA

8. Department of Global Health and Social Medicine, Harvard Medical School, Harvard University, Boston, MA, USA

*Corresponding author:

Zachary J. Ward, MPH

Center for Health Decision Science Harvard T.H. Chan School of Public Health

718 Huntington Ave. 2nd Floor, Boston, MA 02115

Phone: 617-432-2019

Fax: 617-432-0190

Email: zward@hsph.harvard.edu

+Co-senior authors 


\section{Abstract}

Background: Accurate childhood cancer survival estimates are critical for policy-makers and clinicians for priority-setting and planning decisions. However, observed survival estimates are lacking for many countries, and where available, wide variation in outcomes is reported. Understanding the barriers to optimizing survival can help improve childhood cancer outcomes. We aimed to provide estimates of global childhood cancer survival, accounting for the impact of multiple factors that influence cancer outcomes.

Methods: We developed a microsimulation model to simulate childhood cancer survival for 200 countries/territories worldwide, taking into account clinical and epidemiologic factors, including country-specific treatment variables, such as availability of chemotherapy/radiation/surgery. To ensure model results were consistent with reported survival data, we calibrated the model to estimates from the CONCORD 2 and 3 studies using an Approximate Bayesian Computation approach. We estimated five-year net survival for diagnosed childhood cancer cases in each country/territory and estimated potential survival gains if seven policy interventions focused on improving treatment availability and delivery were implemented in isolation or as packages.

Findings: Our model estimates that global five-year net childhood cancer survival is currently $37.4 \%$ (95\% uncertainty interval [UI] 34.7\%-39.8\%), with large variation by region, ranging from $8 \cdot 1 \%$ (95\% UI 4.4\%-13.7\%) in Eastern Africa to 83.0\% (95\% UI 81.6\%-84.4\%) in North America. Among the seven policy interventions modeled, each individually provided limited gains, increasing global five-year net survival to between $38.4 \%$ and $44.6 \%$. When bundled into packages of interventions that either improved service delivery or expanded treatment access, five-year net survival increased to $50 \cdot 2 \%$ (95\% UI $47 \cdot 3 \%$ $53.0 \%$ ) and $54 \cdot 1 \%$ (95\% UI 50.1\%-58.5\%), respectively. A comprehensive systems approach consisting of all policy interventions yielded super-additive gains with global five-year net survival of 53.6\% (95\% UI $51 \cdot 5 \%-55 \cdot 6 \%)$ at $50 \%$ scale-up and $80 \cdot 8 \%$ (95\% UI 79.5\%-82.1\%) at full implementation.

Interpretation: Childhood cancer survival varies widely by region, with especially poor survival in Africa. While expanding access to treatment (chemotherapy/radiation/surgery) and addressing financial toxicity are essential, investments that improve the quality of care, at both the health system and facility-level, are needed to improve childhood cancer outcomes globally.

Funding: Boston Children's Hospital, Dana-Farber Cancer Institute, Harvard T.H. Chan School of Public Health, Harvard Medical School, National Cancer Institute, SickKids, St. Jude Children's Research Hospital, Union for International Cancer Control, Children with Cancer UK Davidson and O'Gorman Fellowship 
Research in context

Evidence before this study

Recent population-based observed data of five-year net childhood cancer survival (ages 0-14 years) for acute lymphoblastic leukemia, lymphomas, and brain tumors from 322 cancer registries globally are provided by the CONCORD-3 study. The CONCORD-2 study previously provided similar population-based five-year net survival estimates for both acute lymphoblastic leukemia and acute myeloid leukemia. We searched PubMed for studies on global childhood cancer survival using the search terms "childhood cancer", "survival", and "global" on Feb 28, 2019, without language or publication date restrictions. We found no other estimates of global childhood cancer survival. While limited observed data from low- and lower middle-income countries are available, it is clear that reported survival varies considerably by region.

Added value of this study

With major geographic and histologic gaps in the observed five-year net survival statistics, there are no global estimates of how many children survive cancer. This study provides, to our knowledge, the first estimate of global childhood cancer survival, based on a simulation model for 200 countries and territories and 48 cancer diagnoses. We provide global, regional, and country-level estimates of fiveyear net cancer survival for all International Classification of Childhood Cancer (Third edition) subgroups and estimate the potential impact of various policy scenarios to help guide priority-setting efforts aimed at improving survival.

Implications of all the available evidence

The estimated gap in childhood cancer five-year net survival between high-income and low-income countries is over 70 percentage points. Thus, the most important prognostic factor for whether a child will survive cancer is where he or she lives. Our model-based findings suggest that while improving the availability of treatments and mitigating abandonment are necessary interventions to achieve high survival, they are insufficient if implemented alone. Concurrent improvements in health systems to achieve better quality of care will also be needed to substantially improve childhood cancer survival worldwide. 
1

2

3

4

5

6

7

9 tumors..$^{3-5}$

10

11

12

\section{Methods}

24 Study design and data sources

\section{Background}

Advances in treatment and supportive care over the past six decades have led to increases in five-year net survival for children diagnosed with cancer (ages 0-14 years) from nearly $0 \%$ to $80 \%$ in high-income countries (HIC) like Great Britain. ${ }^{1}$ While it is generally known that children who develop cancer in lowincome and middle-income countries (LMIC) have not experienced these gains, ${ }^{2}$ the magnitude of the overall survival gap has not been quantified. The best available data, as observed in global populationbased cancer registries, was recently published by the CONCORD study for a subset of childhood cancers: acute lymphoblastic leukemia (ALL), acute myeloid leukemia ( $A M L)$, lymphomas (as a group), and brain Highlighting the survival gap, CONCORD estimates of five-year net survival for ALL, the most common childhood cancer, range from less than $10 \%$ to over $90 \% .{ }^{5}$ However, due to the paucity of cancer registry data from resource-limited settings, only a small subset of CONCORD-3 data (7/322 registries) are from lowincome and lower middle-income countries. Disparities in treatment access, ${ }^{6}$ quality, ${ }^{2}$ and financial toxicity ${ }^{7}$ all contribute to the large global variations in childhood cancer outcomes..$^{2-5,8,9}$

In order to quantify the survival gap and identify opportunities for intervention, we developed a simulation model that synthesizes clinical, epidemiologic, and health system data to estimate country-specific childhood cancer survival. Using the model, we estimate the potential survival gains that could be achieved by addressing barriers to successful treatment, such as availability of treatment modalities and quality of care. These estimates will be used to inform the Lancet Oncology Commission on Sustainable Paediatric Cancer Care, and can assist decision-makers as they prioritize policy interventions that have the potential to improve survival and reduce the number of deaths from childhood cancer. 
25 We developed the Global Childhood Cancer (GCC) microsimulation model to simulate childhood cancer

26 incidence ${ }^{10}$ and survival for 200 countries/territories for 48 cancer subcategories defined by the

27 International Classification of Childhood Cancer, Third edition (ICCC). ${ }^{11}$ The survival module of the GCC

28 model, described here, simulates the clinical course of childhood cancer from diagnosis to five years post-

29 diagnosis, taking into account treatment availability, completion, and quality.

30 We fit the model to observed data by calibrating our model parameters so that our predicted survival

31 estimates were consistent with population-based survival estimates for each cancer and country produced

32 for this study by the CONCORD programme for the global surveillance of cancer survival. ${ }^{3-5}$ We then used a

33 hierarchical approach to infer parameters for countries/diagnoses for which no survival data are available.

34 Using the calibrated model, we estimated current childhood cancer survival for all countries and projected

35 survival gains from expanding access to each treatment modality and improving quality of care. We briefly

36 describe our methods below and provide full details in the appendix.

Procedures

39 We developed a conceptual treatment cascade to account for multiple factors that impact cancer survival

40 from the point of diagnosis to completion of therapy (Figure 1). We assume that a subset of children

41 diagnosed with cancer will achieve five-year survival based on the availability, completion, and quality of

42 treatment. If any required treatment modalities (chemotherapy/radiation/surgery) are unavailable, we

43 assume the child will not survive. We also include a risk of abandoning treatment due to financial toxicity

44 (i.e. financial distress related to the cost of medical care). Lastly, we assume that the quality of care, which

45 depends on a functioning health system with supportive services (e.g. nursing standards, integrated referral

46 and record-keeping) and facility-level activities (e.g. infection control, nutritional support), influences

47 survival. We synthesized information from multiple sources to inform country-specific estimates for each

48 step of the cascade (Table 1). 
49 We used published estimates of diagnosed cancer cases by country and ICCC category from the GCC

50 Incidence module. ${ }^{10}$ These estimates, which take into account geographic variation in cancer incidence and

51 country-specific factors such as demographic trends and health system barriers, are consistent with

52 reported rates of diagnosed cancers in the International Incidence of Childhood Cancer, Volume III (IICC-

53 3). ${ }^{12}$ The GCC Incidence module also provides estimates for countries without registries.

54 For each ICCC diagnosis, we used expert opinion (based on the experience of clinicians with expertise in cancer care in LMIC and specializing in different cancer types (e.g. hematologic cancers, germ cell tumours, solid tumors, etc.)) to specify which treatment components (chemotherapy/radiation/surgical specialties)

57 were necessary for survival. Because stage at diagnosis (which determines necessary treatments for some cancers) is not routinely collected in most cancer registries, as a proxy we estimated the probability of requiring chemotherapy/radiation based on reported treatment numbers from the Surveillance,

60 Epidemiology, and End Results (SEER) program in the US. We also took into account heterogeneity in

61 treatment needs for diagnoses for which a small proportion of patients require chemotherapy/radiation

62 (Appendix pg 3-5).

63 To account for the curability of different cancer types we estimated maximum achievable survival 64 probabilities using data from SEER 2010-2014 to inform the general level and variation of survival by diagnosis. ${ }^{13}$ Because maximum achievable survival in the model assumes availability of all necessary treatment modalities, no abandonment, and optimal quality of care, we inflated the reported SEER

67 estimates to account for the possibility of non-optimal service delivery in the US (Appendix pg 6-7). As calibration targets we obtained country-specific survival estimates for 10 morphology groups from CONCORD (Appendix pg 8). ${ }^{3,5}$ For three brain diagnoses (Astrocytoma, Embryonal, and Other), the

70 CONCORD estimates of survival in the US were substantially higher than those reported in SEER.

71 Specifically, SEER estimates of five-year survival were $80 \%, 68.4 \%$, and $58.9 \%$, respectively, compared to

72 CONCORD estimates of $82 \cdot 7 \%, 69 \cdot 4 \%$, and $96 \cdot 9 \%$. We therefore adjusted our prior probability distributions

73 of maximum achievable survival for these groups to be consistent with the CONCORD estimates. 
74 We used published country-specific estimates to inform the prior probability distributions of treatment

75 variables in the model (Table 1). We estimated priors of the availability of chemotherapy agents based on

76 reported data from a global survey of paediatric oncologists (Appendix pg 10-11). ${ }^{6}$ Estimates of

77 radiotherapy availability were based on coverage estimates from the Lancet Radiotherapy Commission

78 (Appendix pg 12-13). ${ }^{14}$

79 Data for surgical specialties were drawn from multiple sources. For general surgery, we used estimates

80 from a modeling study of the Lancet Surgery Commission (Appendix pg 14-15). ${ }^{15}$ For neurosurgery, we

81 used data on neurosurgeon density from the World Federation of Neurosurgical Societies (Appendix pg 16-

82 17). ${ }^{16}$ Finally, for ophthalmic surgery we used data on the density of ophthalmologists from the World

83 Council of Ophthalmologists (Appendix 18-19). ${ }^{17}$ When sampling country-specific surgery probabilities we

84 assumed that general surgery was the most available type of surgery, followed by ophthalmic surgery, with

85 neurosurgery the least likely to be available.

86 To estimate probabilities of treatment abandonment we used published data from a global survey of

87 paediatric oncologists (Appendix pg 20-21). ${ }^{7}$ We assumed that only patients requiring chemotherapy

88 and/or radiation (thus excluding the few surgery-only groups) were at risk of abandoning treatment due to

89 the prolonged nature of these modalities.

90 Lastly, we included a parameter for 'quality of care', which has been defined as the "degree to which health

91 services for individuals and populations increase the likelihood of desired health outcomes and are

92 consistent with current professional knowledge". ${ }^{18}$ This parameter allows us to account for health system

93 and facility-level factors, capturing residual differences in survival not explained by treatment access or

94 abandonment (Appendix pg 22-23).

95 We used a modified Bayesian hierarchical framework ${ }^{19}$ with three levels (World Bank income group, region, 96 country) to synthesize all available estimates to generate prior probability distributions for all parameters

97 described above. This approach allowed us to regularize the reported data and estimate priors for countries 
98 with no data (see Appendix pg 24 for more details). These priors were used as initial sampling distributions 99 during calibration.

100

101

Outcomes

102 For each country and territory, we modeled the effect of treatment variables on childhood cancer

103 outcomes and estimated five-year net survival for each ICCC diagnosis. We also estimated what five-year

104 net survival would be under various policy interventions aimed at improving survival. We report the mean

105 and $95 \%$ uncertainty intervals (UI) calculated as the 2.5 and 97.5 percentiles of our simulation results.

Statistical analysis

108 Calibration involves comparing model predictions with observed data to identify parameter values that 109 achieve a good fit. ${ }^{20}$ We briefly describe this process here (see Appendix pg 25-56 for full details).

110 We calibrated to CONCORD country/diagnosis-specific five-year net survival estimates, providing 407

111 targets for model calibration. CONCORD-3 estimates of AML survival were reserved as a test set to assess

112 model validity and were not used in calibration. We used an Approximate Bayesian Computation (ABC)

113 approach to fit each country with CONCORD data (65 countries). ${ }^{21}$ For each sampled parameter set we

114 simulated five-year net survival for the number of cancer cases reported for each CONCORD estimate. If the

115 simulated survival probability was within one percentage point of the reported survival estimate we

116 accepted the sampled parameters as a draw from the posterior distribution as per the ABC algorithm. ${ }^{21}$ If a

117 parameter set was not accepted after one million iterations, the best-fitting parameter set for the country

118 was used. For computational efficiency we used simulated annealing ${ }^{22}$ to direct the sampling.

119 For each country, we first tried to fit the model using overall probabilities of chemotherapy availability and 120 treatment abandonment across cancer diagnoses. If the model was unable to fit after 100,000 iterations we

121 allowed these probabilities to vary by diagnosis (see Appendix pg 10-11 and pg 20-21). Automatically

122 introducing flexibility in this way allowed us to fit parsimonious models where possible, while accounting 
123 for variability in the availability and efficacy of diagnosis-specific chemotherapy regimens and

124 abandonment if needed.

125 After fitting each country with calibration targets, we sampled from the posteriors of the hierarchical

126 models to generate parameter values for countries with no CONCORD estimates. This approach allowed us

127 to appropriately reflect country-specific parameter uncertainty while 'borrowing' information from similar

128 countries (i.e. region and income group) when data were not available, similar to approaches used by the

129 Global Burden of Disease and GLOBOCAN for data imputation..$^{89}$ This set of parameter values for all

130 countries and cancers comprises a completed parameter set.

131 We repeated this process to generate 1,000 different parameter sets and scored each set based on how

132 well the model predictions matched the survival targets (based on the distance squared), with each survival

133 target weighted inversely proportional to the width of its confidence interval. We selected the top 100 sets

134 for use in the final model to account for parameter uncertainty.

135 As a posterior predictive check ${ }^{19}$ we compared our predicted survival from the final model to the reported

136 survival estimates from CONCORD. Nearly all (99.0\%) of our prediction intervals (i.e. 95\% UI) overlapped

137 with the $95 \%$ Cls of the CONCORD data, and our prediction intervals contained the reported point estimate

$13887 \cdot 2 \%$ of the time. Our mean predicted survival also fell within the CONCORD $95 \% \mathrm{Cls} 86 \cdot 4 \%$ of the time

139 (Appendix pg 28-47).

140 As a further validity check we compared our predictions of AML survival to estimates for 48 countries from

141 CONCORD-3. These estimates were not used to calibrate the model, so they can serve as an external

142 validity check of our model predictions. Our prediction intervals (95\% UI) overlapped with the CONCORD-3

143 AML $95 \%$ Cls $97 \cdot 9 \%$ of the time, contained the reported point estimate (i.e. coverage probability) $81 \cdot 3 \%$ of

144 time, and our mean predicted survival fell within the $95 \% \mathrm{Cls} 77 \cdot 0 \%$ of the time (Appendix pg 54-55).

145 Using the best-fitting 100 parameter sets we estimated five-year net cancer survival for each diagnosis. We 146 ran 1,000 simulations from 2015 to 2019 to estimate survival over this period, in each iteration sampling a 
147 good-fitting parameter set to account for parameter (second-order) uncertainty and simulating the number

148 of diagnosed cases $^{10}$ and individual-level survival to account for first-order uncertainty. ${ }^{23}$

149 To explore the impact of treatment barriers (treatment availability, abandonment, and quality of care), we

150 simulated counterfactual interventions in which we replaced the relevant parameter for each country with

151 the mean estimated parameter among high income countries (Table 2). We also simulated packages of

152 policy interventions to explore the relative impact of expanding treatment access vs. improving service

153 delivery, and a comprehensive approach addressing all treatment barriers. We estimated five-year net

154 childhood cancer survival for each scenario. The GCC model was coded in Java (version 1.8.0), and statistical

155 analyses were performed in R (version 3.3.1).

Role of the funding source

158 The funders of the study had no role in study design, data collection, data analysis, data interpretation, or 159 writing of the report. All authors had full access to all the data used in the study. The corresponding author 160 had final responsibility for the decision to submit for publication.

\section{Results}

163 We estimate that globally, for children diagnosed in 2015, five-year net survival for all cancers combined 164 was $37 \cdot 4 \%$ (95\% UI 34.7\%-39.8\%), with large variation by region, ranging from $8 \cdot 1 \%$ (95\% UI 4.4\%-13.7\%)

165 in Eastern Africa to 83.0\% (95\% UI 81.6\%-84.4\%) in North America (Figure 2). Detailed survival estimates by 166 diagnosis and continent for all 48 ICCC categories are presented in Figure 3. These estimates reveal large 167 variation within cancer-specific survival, with survival gaps of over 80 percentage points for cancers such as 168 Hodgkin lymphoma and retinoblastoma that have high survival in North America but very poor survival in 169 Africa. See Appendix pg 57-257 for complete country-/diagnosis-specific survival estimates.

170 We find that among individual policy interventions, efforts to improve the quality of care could yield the 171 largest potential survival gains globally (five-year net survival of $44 \cdot 6 \%$ [95\% UI 41-7\%-47-4\%], an increase of 
$1727 \cdot 2 \%)$, followed by expanding access to general surgery (42.7\% [95\% UI 39.9\%-45·6\%], 5·3\% increase) and

173 chemotherapy (41.9\% [95\% UI 38.9\%-45.0\%], 4.5\% increase) (Table 3). This general pattern is similar across

174 most regions of the world.

175 Looking at policy intervention packages, we find that increasing the availability of all treatments to the level

176 of HIC has a significant, though still relatively modest effect on global five-year net survival (54.1\% [ $95 \%$ UI

$17750 \cdot 1 \%-58 \cdot 5 \%]$ ). Similarly, improving service delivery (i.e. simultaneously improving quality of care and

178 reducing abandonment) yields important survival gains, but to a lesser extent (50-2\% [95\% UI 47-3\%-

$17953.0 \%])$.We see however that improving both treatment access and service delivery has a super-additive

180 effect. For example, closing the gap with HIC for all components by $50 \%$ is predicted to achieve similar or

181 larger gains in global five-year net survival (53.6\% [95\% UI 51·5\%-55.6\%]) compared to $100 \%$ scale-up of

182 treatment access or service delivery packages separately (Table 3). Full implementation of all interventions

183 is estimated to increase global five-year net survival to $80 \cdot 8 \%$ (95\% UI 79.5\%-82-1\%).

185 Discussion

186 Using rigorous statistical and computational methods to synthesize estimates from multiple sources of 187 data, we developed a model of childhood cancer survival for 200 countries/territories worldwide. We find 188 that childhood cancer survival varies widely by country due to substantial differences in access to 189 multidisciplinary treatment modalities, abandonment rates, and quality of care. As a result, our findings 190 suggest that five-year net survival for all childhood cancers combined varies by up to 75 percentage points 191 between World Health Organization (WHO) sub-regions (Table 3). Furthermore, as net survival only 192 considers deaths from cancer, the gap in total survival is likely even larger given higher risks of competing 193 mortality in LMIC. Although genetic variations are known to impact survival, ${ }^{24,25}$ the most important 194 prognostic factor today for whether a child diagnosed with cancer will survive is not related to cancer 195 biology, but is instead the country where they receive treatment. 
196 Beyond their importance for policy-making and informing health investment decisions by countries and

197 development agencies, these estimates can provide a baseline assessment to help guide efforts to improve 198 childhood cancer policies and those aimed at building stronger health systems. For example, the WHO

199 Global Initiative for Childhood Cancer, announced in September $2018,{ }^{26}$ aims to increase global childhood

200 cancer survival to $60 \%$ by 2030 , as measured by six tracer cancer subtypes: ALL, Hodgkin lymphoma, Burkitt

201 lymphoma, retinoblastoma, nephroblastoma, and low-grade gliomas. Our estimates of five-year net

202 survival for ALL (56.1\%) and Hodgkin lymphoma (44.6\%) suggest moderate improvement is required for

203 these cancers to achieve 60\% survival. However, our survival estimates for the other cancers are much

204 lower, with retinoblastoma, Burkitt, and nephroblastoma all around 25\% (Figure 3). (It is not possible to

205 estimate survival for low-grade gliomas with the current ICCC categories.)

206 In contrast, we estimate five-year net survival for these cancers to be $90 \%$ or higher in North America,

207 highlighting both the opportunity to substantially increase survival and the challenge of achieving these

208 gains in a relatively short period of time. However, given that nearly half of children with cancer may fail to

209 be diagnosed in $\mathrm{LMIC},{ }^{10}$ the true overall survival rate is likely even lower. Therefore, in addition to

210 improving treatment, increased efforts to identify all cases in a population and develop stronger health

211 systems with appropriate support services will also be needed to improve survival for all children with

212 cancer.

213 To address the stark global disparities in childhood cancer survival, determining which policy interventions

214 are likely to be most effective is a necessary first step. Individually, our model predicts that single policy

215 interventions alone will yield limited survival gains. While efforts to address any one problem, such as

216 financial toxicity, are necessary to achieve high survival, they are insufficient if implemented alone. In

217 particular, we find that while reducing abandonment results in more children completing therapy, overall

218 survival does not significantly improve due to interdependencies in the availability of treatment modalities

219 and quality of care. Although abandonment represents an important actionable opportunity, ensuring 
220 patient retention and completion of therapy is inefficient if the quality of care is not also improved to

221 reduce treatment-related toxicity.

222 Our findings instead highlight the importance of complex interdependencies in childhood cancer treatment.

223 We find that comprehensive packages of policy interventions that improve both treatment access and

224 service delivery yield synergistic survival gains. Thus, a key message is that a systems approach with

225 packages of policy interventions including investments to expand access to multidisciplinary care, reduce

226 financial toxicity, and improve service delivery are necessary to substantially improve cancer survival. In a

227 follow-up analysis we are estimating the return on investment of implementing such a comprehensive

228 approach, taking into account the costs of health system strengthening to improve care for children with

229 cancer.

230 Beyond the interdependence of policy interventions, the model also highlights the importance that quality

231 of care plays in improving childhood cancer outcomes. These findings are not unique to paediatric cancer,

232 as the importance of quality is echoed in results from other areas of global health as well. For example, a

233 conditional cash-transfer program incentivizing facility childbirth in India succeeded in substantially

234 expanding access to healthcare, but failed to reduce maternal mortality due to a lack of focus on quality. ${ }^{27}$

235 Similarly, improving childhood cancer outcomes worldwide will require paying attention to what happens

236 once children reach healthcare facilities, with investments to measure and improve healthcare quality in

237 addition to expanding access. ${ }^{28}$

238 The widespread impact of quality, from the patient level to the health system means that a broad range of

239 initiatives is needed. For example, at the facility level, supportive care-related interventions (e.g. infection

240 control and nutritional programs) designed to reduce death due to comorbidities are critical to improve

241 service delivery and safety. Although generic guidelines promoting the importance of supportive care

242 measures have been published, ${ }^{29}$ specific quality improvement initiatives that reflect the local context need

243 to be designed and evaluated. Improving the quality of care also requires higher-level improvements to the

244 overall health system (e.g. workforce planning and efficient referral patterns). A focus on quality at all levels 
245 of the health system is thus needed to achieve integrated care that is person-centered and responsive to

246 the patient's needs.

$248 \quad$ Limitations

249 While our modeling approach allows us to synthesize data from multiple sources in a way that is consistent

250 with data on treatment availability and reported survival, there are a number of limitations due to the

251 assumptions needed for model development. First, much of our data is based on cross-sectional surveys of

252 treatment access and abandonment that may provide an incomplete snapshot of the reality on the ground.

253 For example, our prior probabilities (i.e. pre-calibration) of abandonment are based on survey data which

254 reported estimates for ALL only, ${ }^{7}$ and the survey data used to inform chemotherapy priors may not be

255 representative of the respondents' countries as a whole. However, our approach allowed us to account for

256 uncertainty around all model parameters, as well as their joint distribution. Our $95 \%$ uncertainty intervals

257 thus reflect the sensitivity of our results to different parameter estimates. However, it should be noted that

258 while these intervals capture the statistical uncertainty around the model parameters and calibration

259 targets, they do not include uncertainty due to other factors, such as our modelling assumptions and

260 potential data quality issues in the calibration targets used to fit the model.

261 Second, although we used hierarchical models to incorporate all available observed data, the paucity of

262 registries in LMIC and small sample sizes in some regions may have affected our results, and contribute to

263 the wide uncertainty intervals we report for some cancers and countries. For example, CONCORD survival

264 estimates were only available for two countries in sub-Saharan Africa (Nigeria and Lesotho), and then only

265 for ALL.

266 Third, due to lack of data we used a single quality parameter per country as a proxy for many factors

267 related to service delivery. In some countries this constraint meant it was not possible to fit all calibration

268 targets. However, our approach allows us to refine and update our model as more specific data become

269 available. While abstract, our estimates of quality are similar to other published estimates and are highly 
270 correlated ( $r=0 \cdot 83$ ) with the Global Burden of Disease Healthcare Access and Quality Index (HAQI)

271 (Appendix pg 56). ${ }^{30}$ Given that our quality parameters were inferred exclusively by model calibration this

272 builds confidence in the convergent validity of our estimates.

273 Lastly, while calibration allowed us to align our model results with observed survival and induce appropriate

274 covariance between model parameters, due to lack of data we assumed that the availability of each

275 treatment modality was independent for each individual patient. In the future, facility-level data would

276 help to refine this assumption and account for correlation between the availability of treatment options for

277 a given patient. In addition, these types of data could also help inform more specific quality measures to

278 include in the model to track progress more precisely.

279 Notwithstanding these limitations, using a model-based approach, we provide, to our knowledge, the first

280 global estimate of childhood cancer survival and find large disparities in five-year net survival as a result of

281 substantial differences in access to multidisciplinary treatment modalities, abandonment rates, and quality

282 of care. Our findings suggest that while increasing access to treatment is necessary to achieve high survival,

283 it is not sufficient. A comprehensive set of policy interventions, including expanding treatment access,

284 reducing abandonment, and improving quality of care in health systems are needed to reduce the large

285 disparities in childhood cancer survival and substantially reduce childhood cancer deaths worldwide. 


\section{Contributors}

ZJW, JMY, NB, ALF, and RA designed the study and acquired the data. FG provided insight on morphology groupings and additional survival estimates from the CONCORD programme. ZJW performed the analyses. All authors interpreted the results and contributed to the writing of the report.

\section{Declaration of interests}

We declare no competing interests.

\section{Acknowledgements:}

This study was funded by Boston Children's Hospital, Dana-Farber Cancer Institute, Harvard T.H. Chan School of Public Health, Harvard Medical School, National Cancer Institute, SickKids, St. Jude Children's Research Hospital, Union for International Cancer Control, and Children with Cancer UK Davidson and O'Gorman Fellowship. We gratefully acknowledge other investigators of the CONCORD programme, Claudia Allemani, Michel Coleman and Veronica Di Carlo for their contribution in interpreting the country and disease-specific survival data, Carlos Rodriguez-Galindo and Paola Friedrich for clinical input on treatment regimens, and for Paola's help in sharing and contextualizing treatment abandonment data, Phillip Cohen for providing survey data on chemotherapy drug availability, and Blake Alkire for country-level general surgery availability data.

\section{References}

1. Shah A, Coleman MP. Increasing incidence of childhood leukaemia: a controversy re-examined. Br J Cancer 2007; 97: 1009-1012.

2. Rodriguez-Galindo C, Friedrich P, Alcasabas P, et al. Toward the Cure of All Children with Cancer Through Collaborative Efforts: Pediatric Oncology As a Global Challenge. J Clin Oncol 2015; 33(27): 3065-73. 
3. Bonaventure A, Harewood R, Stiller CA, et al. World wide comparison of survival from childhood leukaemia for 1995-2009, by subtype, age, and sex (CONCORD-2): a population-based study of individual data for 89828 children from 198 registries in 53 countries. Lancet Haematol 2017; 4(5): e202-e217.

4. Allemani C, Weir HK, Carreira H, et al. Global surveillance of cancer survival 1995-2009: analysis of individual data for $25,676,887$ patients from 279 population-based registries in 67 countries (CONCORD2). Lancet 2015; 385(9972): 977-1010.

5. Allemani C, Matsuda T, Di Carlo V, et al. Global surveillance of trends in cancer survival 2000-14 (CONCORD-3): analysis of individual records 37,513,025 patients diagnosed with one of 18 cancers from 322 population-based registries in 71 countries. Lancet 2018; 391(10125): 1023-1075.

6. Cohen P, Friedrich P, Lam C, et al. Global Access to Essential Medicines for Childhood Cancer: A CrossSectional Survey. JGO 2019; 4: 1-11.

7. Friedrich P, Lam CG, Itriago E, Perez R, Ribeiro RC, Arora RS. Magnitude of Treatment Abandonment in Childhood Cancer. PLoS ONE 2015; 10(9): e0135230.

8. Global Burden of Disease Cancer Collaboration, Fitzmaurice C, Allen C, et al. Global, Regional, and National Cancer Incidence, Mortality, Years of Life Lost, Years Lived With Disability, and DisabilityAdjusted Life-years for 32 Cancer Groups, 1990 to 2015: A Systematic Analysis for the Global Burden of Disease Study. JAMA Oncol 2017; 3(4): 524-548.

9. Ferlay J, Soerjomataram I, Dikshit R, et al. Cancer incidence and mortality worldwide: sources, methods and major patterns in GLOBOCAN 2012. Int J Cancer 2015; 136(5): E359-86.

10. Ward ZJ, Yeh JM, Bhakta N, Frazier AL, Atun R. Estimating the total incidence of global childhood cancer - a simulation-based analysis. Lancet Oncol. In Press.

11. Steliarova-Foucher E, Stiller CA, Lacour B, Kaatsch P. International Classification of Childhood Cancer, Third Edition. Cancer 2005; 103: 1457-67. 
12. Steliarova-Foucher E, Colombet M, Ries LAG, et al. [editors] (2017). International Incidence of Childhood Cancer, Volume III (electronic version). Lyon, France: International Agency for Research on Cancer. Available at: http://iicc.iarc.fr/results/ [accessed 17 May 2018].

13. Surveillance, Epidemiology, and End Results (SEER) Program (www.seer.cancer.gov) SEER*Stat Database: Incidence - SEER 9 Regs Research Data, Nov 2017 Sub (1973-2015) <Katrina/Rita Population Adjustment> - Linked To County Attributes - Total U.S., 1969-2016 Counties, National Cancer Institute, DCCPS, Surveillance Research Program, released April 2018, based on the November 2017 submission.

14. Atun R, Jaffray DA, Barton MB, et al. Expanding global access to radiotherapy. Lancet Oncol 2015; 16(10): 1153-86.

15. Alkire BC, Raykar NP, Shrime MG, et al. Global access to surgical care: a modelling study. Lancet Glob Health 2015; 3(6): e316-23.

16. World Federation of Neurosurgical Societies. Global Neurosurgical Workforce Map 2016. Available at: https://wfns.org/menu/61/global-neurosurgical-workforce-map [accessed 21 September 2018].

17. Resnikoff S, Felch W, Gauthier TM, Spivey B. The number of ophthalmologists in practice and training worldwide: a growing gap despite more than 200,000 practitioners. Br J Ophthalmol 2012; 96(6): 783-7.

18. Institute of Medicine. Medicare: A Strategy for Quality Assurance. Washington DC: National Academy Press; 1990.

19. Gelman A, Carlin JB, Stern HS, Rubin DB. Bayesian Data Analysis. $3^{\text {rd }}$ Edn. Boca Raton, FL: CRC Press; 2014.

20. Vanni T, Karnon J, Madan J, et al. Calibrating models in economic evaluation: a seven step approach. Pharmacoeconomics 2011; 29: 35-49.

21. Kypraios T, Neal P, Prangle D. A tutorial introduction to Bayesian inference for stochastic epidemic models using Approximate Bayesian Computation. Math Biosci 2017; 287: 42-53.

22. Kirkpatrick S, Gelatt CD, Vecchi MP. Optimization by Simulated Annealing. Science 1983; 220: 671-80. 
23. Briggs AH, Weinstein MC, Fenwick EA, Karnon J, Sculpher MJ, Paltiel AD. Model parameter estimation and uncertainty analysis: a report of the ISPOR-SMDM Modeling Good Research Practices Task Force Working Group-6. Med Decis Making 2012; 23: 722-32.

24. Moriyama T, Yang YL, Nishii R, Ariffin H, Liu C, Lin TN, et al. Novel variants in NUDT15 and thiopurine intolerance in children with acute lymphoblastic leukemia from diverse ancestry. Blood 2017; 130(10): 12019-1212.

25. Yang JJ, Cheng C, Devidas M, Cao X, Fan Y, Campana D, et al. Ancestry and pharmacogenomics of relapse in acute lymphoblastic leukemia. Nat Genet 2011; 43(3): 237-41.

26. World Health Organization. Global Initiative for Childhood Chancer. Available at: https://www.who.int/cancer/childhood-cancer/en/ [accessed 11 December 2018].

27. Randive B, Diwan V, De Costa A. India's conditional cash transfer programme (the JSY) to promote institutional birth: is there an association between institutional birth proportion and maternal mortality? PLoS One 2013; 8: e67452.

28. Kruk ME, Larson E, Twum-Danso NA. Time for a quality revolution in global health. Lancet Glob Health 2016; 4(9): e594-6.

29. Israels T, Renner L, Hendricks M, Hesseling P, Howard S, Molyneux E. SIOP PODC: Recommendations for Supportive Care of Children With Cancer in a Low-Income Setting. Pediatr Blood Cancer 2013; 60: 899904.

30. GBD 2015 Healthcare Access and Quality Collaborators. Healthcare Access and Quality Index based on mortality from causes amenable to personal health care in 195 countries and territories, 1990-2015: a novel analysis from the Global Burden of Disease Study 2015. Lancet 2017; 390(10091): 231-266. 
Table 1: Overview of GCC Survival Module country-specific data sources

\begin{tabular}{|c|c|c|c|}
\hline $\begin{array}{l}\text { Model } \\
\text { Parameter }\end{array}$ & Data Source & $\begin{array}{l}\text { \# Model } \\
\text { Countries } \\
\text { Reported }\end{array}$ & Reference \\
\hline \multicolumn{4}{|c|}{ Cancer Diagnosis } \\
\hline $\begin{array}{c}\text { Diagnosed } \\
\text { cancer cases }\end{array}$ & $\begin{array}{l}\text { Estimated annual diagnosed cases by } \\
\text { ICCC subgroup }\end{array}$ & 200 & GCC Incidence Module ${ }^{10}$ \\
\hline \multicolumn{4}{|l|}{ Cancer Survival } \\
\hline $\begin{array}{c}\text { Necessary } \\
\text { treatment } \\
\text { components } \\
\end{array}$ & $\begin{array}{c}\text { Expert opinion; SEER estimates of } \\
\text { chemotherapy/radiation used as proxy } \\
\text { for cancer stage }\end{array}$ & 1 (US) & $\begin{array}{c}\text { SEER }^{13} \\
\text { (Appendix pg 3-5) }\end{array}$ \\
\hline $\begin{array}{c}\text { Maximum } \\
\text { achievable } \\
\text { survival }\end{array}$ & $\begin{array}{l}\text { SEER 2010-2014 five-year relative } \\
\text { survival used as initial proxy }\end{array}$ & 1 (US) & $\begin{array}{c}\text { SEER }^{13} \\
\text { (Appendix pg 6-7) }\end{array}$ \\
\hline $\begin{array}{c}\text { Population- } \\
\text { based survival }\end{array}$ & $\begin{array}{l}\text { Five-year net survival by country, } \\
\text { derived from cancer registry data }\end{array}$ & $\begin{array}{l}10-64 \text { (varies } \\
\text { by diagnosis) }\end{array}$ & $\begin{array}{c}\text { CONCORD }^{3,5} \\
\text { (Appendix pg 8) }\end{array}$ \\
\hline \multicolumn{4}{|c|}{ Cancer Treatment } \\
\hline $\begin{array}{l}\text { Chemotherapy } \\
\text { availability }\end{array}$ & Reported availability of chemotherapy & 94 & $\begin{array}{l}\text { Published survey data }{ }^{6} \\
\text { (Appendix pg 10-11) }\end{array}$ \\
\hline $\begin{array}{l}\text { Radiation } \\
\text { availability }\end{array}$ & Radiotherapy coverage & 173 & $\begin{array}{c}\text { Lancet Radiotherapy Commission }^{14} \\
\text { (Appendix pg 12-13) }\end{array}$ \\
\hline $\begin{array}{c}\text { Surgery } \\
\text { availability }\end{array}$ & $\begin{array}{l}\text { Availability of general surgery } \\
\text { Neurosurgeon density } \\
\text { Ophthalmologist density }\end{array}$ & $\begin{array}{l}184 \\
192 \\
192\end{array}$ & $\begin{array}{l}\text { Lancet Global Surgery Commission }{ }^{15} \\
\text { (Appendix pg 14-15) } \\
\text { World Federation of Neurosurgical } \\
\text { Societies }{ }^{16} \text { (Appendix pg 16-17) } \\
\text { International Council of Ophthalmology }{ }^{17} \\
\text { (Appendix pg 18-19) }\end{array}$ \\
\hline $\begin{array}{c}\text { Treatment } \\
\text { abandonment }\end{array}$ & Probability of treatment abandonment & 98 & $\begin{array}{l}\text { Published survey data } \\
\text { (Appendix pg 20-21) }\end{array}$ \\
\hline
\end{tabular}


Table 2: Policy Intervention Scenarios

\begin{tabular}{|c|c|}
\hline Scenario Name & Description of Policy Intervention \\
\hline Baseline & (No change from baseline) \\
\hline \multicolumn{2}{|c|}{ Individual Policy Intervention } \\
\hline Chemotherapy & Increase availability of chemotherapy to mean of HIC \\
\hline Radiation & Increase availability of radiation to mean of HIC \\
\hline General Surgery & Increase availability of general surgery to mean of HIC \\
\hline Neurosurgery & Increase availability of neurosurgery to mean of HIC \\
\hline Ophthalmology & Increase availability of ophthalmic surgery for Retinoblastoma to mean of HIC \\
\hline Abandonment & Reduce treatment abandonment to mean of $\mathrm{HIC}$ \\
\hline Quality of Care & Improve quality of care to mean of HIC \\
\hline \multicolumn{2}{|c|}{ Packages of Policy Interventions } \\
\hline $\begin{array}{l}\text { Expand Treatment } \\
\text { Access }\end{array}$ & $\begin{array}{l}\text { Increase availability of all treatment modalities (chemotherapy, radiation, surgery and } \\
\text { surgical subspecialties) to mean of HIC }\end{array}$ \\
\hline $\begin{array}{l}\text { Improve Service } \\
\text { Delivery }\end{array}$ & Improve quality of care while reducing abandonment rates to mean of HIC \\
\hline $\begin{array}{l}\text { Comprehensive - } \\
50 \%\end{array}$ & $\begin{array}{l}\text { Expand treatment access and improve service delivery to close the gap with mean of HIC by } \\
\qquad 50 \%\end{array}$ \\
\hline $\begin{array}{l}\text { Comprehensive - } \\
\quad 100 \%\end{array}$ & $\begin{array}{l}\text { Expand treatment access and improve service delivery to close the gap with mean of HIC by } \\
\qquad 100 \%\end{array}$ \\
\hline
\end{tabular}

$\mathrm{HIC}=$ High Income Countries 
Table 3: Estimated Childhood Cancer Five-Year Net Survival 2015-2019 (\%) Under Various Policy Interventions*

\begin{tabular}{|c|c|c|c|c|c|c|c|c|c|c|c|c|}
\hline \multirow[b]{2}{*}{ Area } & \multirow[b]{2}{*}{ Baseline } & \multicolumn{5}{|c|}{ Single Intervention - Treatment Access } & \multicolumn{2}{|c|}{$\begin{array}{l}\text { Single Intervention - } \\
\text { Service Delivery }\end{array}$} & \multirow[b]{2}{*}{$\begin{array}{l}\text { Expand } \\
\text { Treatment } \\
\text { Access }\end{array}$} & \multicolumn{2}{|c|}{ Intervention Packages } & \multirow[b]{2}{*}{$\begin{array}{c}\text { Comprehe } \\
\text { nsive - } \\
100 \%^{+}\end{array}$} \\
\hline & & Chemotherapy & Radiation & $\begin{array}{l}\text { General } \\
\text { Surgery }\end{array}$ & $\begin{array}{l}\text { Neuro- } \\
\text { surgery }\end{array}$ & $\begin{array}{c}\text { Ophthalmic } \\
\text { Surgery }\end{array}$ & $\begin{array}{c}\text { Abandon- } \\
\text { ment }\end{array}$ & $\begin{array}{l}\text { Quality of } \\
\text { Care }\end{array}$ & & $\begin{array}{l}\text { Improve } \\
\text { Service } \\
\text { Delivery }\end{array}$ & $\begin{array}{c}\text { Comprehe } \\
\text { nsive - } \\
50 \%^{+}\end{array}$ & \\
\hline GLOBAL & $\begin{array}{c}37 \cdot 4 \\
(34 \cdot 7-39 \cdot 8)\end{array}$ & $\begin{array}{c}41.9 \\
(38.9-45 \cdot 0)\end{array}$ & $\begin{array}{c}39 \cdot 1 \\
(36 \cdot 4-41 \cdot 5)\end{array}$ & $\begin{array}{c}42 \cdot 7 \\
(39 \cdot 9-45 \cdot 6)\end{array}$ & $\begin{array}{c}39 \cdot 0 \\
(36 \cdot 3-41 \cdot 6)\end{array}$ & $\begin{array}{c}38 \cdot 4 \\
(35 \cdot 8-40 \cdot 9)\end{array}$ & $\begin{array}{c}41 \cdot 1 \\
(37 \cdot 8-44 \cdot 4)\end{array}$ & $\begin{array}{c}44 \cdot 6 \\
(41 \cdot 7-47 \cdot 4)\end{array}$ & $\begin{array}{c}54 \cdot 1 \\
(50 \cdot 1-58 \cdot 5)\end{array}$ & $\begin{array}{c}50 \cdot 2 \\
(47 \cdot 3-53 \cdot 0)\end{array}$ & $\begin{array}{c}53.6 \\
(51.5-55.6)\end{array}$ & $\begin{array}{c}80 \cdot 8 \\
(79.5-82 \cdot 1)\end{array}$ \\
\hline Low income & $\begin{array}{c}7 \cdot 4 \\
(5 \cdot 0-10 \cdot 7)\end{array}$ & $\begin{array}{c}10 \cdot 0 \\
(6 \cdot 6-14 \cdot 5)\end{array}$ & $\begin{array}{c}9.4 \\
(6 \cdot 4-13 \cdot 4)\end{array}$ & $\begin{array}{c}15 \cdot 5 \\
(10 \cdot 8-20 \cdot 6)\end{array}$ & $\begin{array}{c}7 \cdot 7 \\
(5 \cdot 2-11 \cdot 1)\end{array}$ & $\begin{array}{c}8.6 \\
(5 \cdot 9-12 \cdot 1)\end{array}$ & $\begin{array}{c}12 \cdot 2 \\
(8 \cdot 7-16 \cdot 5)\end{array}$ & $\begin{array}{c}14 \cdot 4 \\
(11 \cdot 0-18 \cdot 2)\end{array}$ & $\begin{array}{c}26 \cdot 5 \\
(18 \cdot 3-35 \cdot 4)\end{array}$ & $\begin{array}{c}23 \cdot 9 \\
(20 \cdot 0-27 \cdot 8)\end{array}$ & $\begin{array}{c}29 \cdot 4 \\
(25 \cdot 8-33 \cdot 4)\end{array}$ & $\begin{array}{c}80 \cdot 6 \\
(77 \cdot 2-83 \cdot 3)\end{array}$ \\
\hline $\begin{array}{l}\text { Lower middle } \\
\text { income }\end{array}$ & $\begin{array}{c}24 \cdot 0 \\
(19 \cdot 5-29 \cdot 1)\end{array}$ & $\begin{array}{c}29 \cdot 2 \\
(23 \cdot 4-34 \cdot 3)\end{array}$ & $\begin{array}{c}26 \cdot 1 \\
(21 \cdot 1-31 \cdot 6)\end{array}$ & $\begin{array}{c}31 \cdot 9 \\
(26 \cdot 2-38 \cdot 2)\end{array}$ & $\begin{array}{c}26 \cdot 0 \\
(21 \cdot 1-31 \cdot 5)\end{array}$ & $\begin{array}{c}25 \cdot 5 \\
(20 \cdot 9-30 \cdot 8)\end{array}$ & $\begin{array}{c}28 \cdot 5 \\
(22 \cdot 6-34 \cdot 8)\end{array}$ & $\begin{array}{c}33 \cdot 6 \\
(28 \cdot 7-38 \cdot 3)\end{array}$ & $\begin{array}{c}46.5 \\
(38 \cdot 0-53.9)\end{array}$ & $\begin{array}{c}40 \cdot 8 \\
(36 \cdot 7-45 \cdot 3)\end{array}$ & $\begin{array}{c}45 \cdot 4 \\
(41 \cdot 7-49 \cdot 2)\end{array}$ & $\begin{array}{c}80 \cdot 6 \\
(78.9-82 \cdot 1)\end{array}$ \\
\hline $\begin{array}{l}\text { Upper middle } \\
\text { income }\end{array}$ & $\begin{array}{c}55.5 \\
(51.5-58.9)\end{array}$ & $\begin{array}{c}61 \cdot 5 \\
(55 \cdot 6-67 \cdot 1)\end{array}$ & $\begin{array}{c}56 \cdot 9 \\
(52 \cdot 8-60 \cdot 5)\end{array}$ & $\begin{array}{c}57 \cdot 4 \\
(54 \cdot 1-60 \cdot 6)\end{array}$ & $\begin{array}{c}57 \cdot 5 \\
(54 \cdot 0-60 \cdot 4)\end{array}$ & $\begin{array}{c}55 \cdot 9 \\
(52 \cdot 1-59 \cdot 2)\end{array}$ & $\begin{array}{c}58 \cdot 4 \\
(53 \cdot 7-63 \cdot 1)\end{array}$ & $\begin{array}{c}61 \cdot 9 \\
(55 \cdot 9-68 \cdot 1)\end{array}$ & $\begin{array}{c}68 \cdot 2 \\
(61 \cdot 7-73 \cdot 5)\end{array}$ & $\begin{array}{c}65 \cdot 2 \\
(59 \cdot 5-71 \cdot 5)\end{array}$ & $\begin{array}{c}66 \cdot 9 \\
(64 \cdot 4-69 \cdot 1)\end{array}$ & $\begin{array}{c}80 \cdot 2 \\
(78.8-81 \cdot 6)\end{array}$ \\
\hline High income & $\begin{array}{c}79 \cdot 8 \\
(78 \cdot 7-80 \cdot 8)\end{array}$ & $\begin{array}{c}80 \cdot 6 \\
(79 \cdot 6-81 \cdot 7)\end{array}$ & $\begin{array}{c}80 \cdot 0 \\
(78 \cdot 9-81 \cdot 0)\end{array}$ & $\begin{array}{c}80 \cdot 2 \\
(79 \cdot 2-81 \cdot 3)\end{array}$ & $\begin{array}{c}80 \cdot 3 \\
(79 \cdot 2-81 \cdot 3)\end{array}$ & $\begin{array}{c}79.9 \\
(78.8-80.9)\end{array}$ & $\begin{array}{c}80 \cdot 4 \\
(79 \cdot 4-81 \cdot 5)\end{array}$ & $\begin{array}{c}80 \cdot 2 \\
(79 \cdot 2-81 \cdot 3)\end{array}$ & $\begin{array}{c}81 \cdot 7 \\
(80 \cdot 7-82 \cdot 8)\end{array}$ & $\begin{array}{c}80 \cdot 9 \\
(79.9-81.9)\end{array}$ & $\begin{array}{c}81 \cdot 3 \\
(80 \cdot 3-82 \cdot 4)\end{array}$ & $\begin{array}{c}82.9 \\
(82.0-83.9)\end{array}$ \\
\hline Africa & $\begin{array}{c}11 \cdot 6 \\
(8 \cdot 7-14 \cdot 8)\end{array}$ & $\begin{array}{c}14 \cdot 1 \\
(10 \cdot 5-18 \cdot 1)\end{array}$ & $\begin{array}{c}13 \cdot 4 \\
(10 \cdot 1-17 \cdot 1)\end{array}$ & $\begin{array}{c}19 \cdot 0 \\
(13 \cdot 9-25 \cdot 1)\end{array}$ & $\begin{array}{c}12 \cdot 0 \\
(9 \cdot 0-15 \cdot 4)\end{array}$ & $\begin{array}{c}13 \cdot 1 \\
(9 \cdot 8-16.9)\end{array}$ & $\begin{array}{c}16 \cdot 2 \\
(12 \cdot 0-21 \cdot 4)\end{array}$ & $\begin{array}{c}21 \cdot 0 \\
(18 \cdot 0-24 \cdot 5)\end{array}$ & $\begin{array}{c}29 \cdot 0 \\
(21 \cdot 4-37 \cdot 6)\end{array}$ & $\begin{array}{c}30 \cdot 4 \\
(26 \cdot 8-34 \cdot 0)\end{array}$ & $\begin{array}{c}33.7 \\
(30 \cdot 2-37 \cdot 4)\end{array}$ & $\begin{array}{c}80.9 \\
(77.9-83.5)\end{array}$ \\
\hline Eastern Africa & $\begin{array}{c}8 \cdot 1 \\
(4 \cdot 4-13 \cdot 7)\end{array}$ & $\begin{array}{c}10 \cdot 5 \\
(5 \cdot 5-17 \cdot 5)\end{array}$ & $\begin{array}{c}10 \cdot 7 \\
(5.9-18.0)\end{array}$ & $\begin{array}{c}15 \cdot 3 \\
(8 \cdot 7-23 \cdot 7)\end{array}$ & $\begin{array}{c}8 \cdot 3 \\
(4 \cdot 6-14 \cdot 1)\end{array}$ & $\begin{array}{c}8 \cdot 8 \\
(4 \cdot 9-14 \cdot 7)\end{array}$ & $\begin{array}{c}13 \cdot 0 \\
(7 \cdot 5-19 \cdot 6)\end{array}$ & $\begin{array}{c}15 \cdot 4 \\
(11 \cdot 0-20 \cdot 8)\end{array}$ & $\begin{array}{c}26 \cdot 3 \\
(14 \cdot 9-41 \cdot 9)\end{array}$ & $\begin{array}{c}25 \cdot 1 \\
(19 \cdot 6-30 \cdot 8)\end{array}$ & $\begin{array}{c}29 \cdot 7 \\
(24 \cdot 5-36 \cdot 0)\end{array}$ & $\begin{array}{c}80 \cdot 2 \\
(75 \cdot 5-83 \cdot 4)\end{array}$ \\
\hline Southern Africa & $\begin{array}{c}19 \cdot 2 \\
(11 \cdot 9-26 \cdot 1)\end{array}$ & $\begin{array}{c}21 \cdot 7 \\
(13 \cdot 9-30 \cdot 1)\end{array}$ & $\begin{array}{c}22 \cdot 3 \\
(14 \cdot 6-30 \cdot 5)\end{array}$ & $\begin{array}{c}22 \cdot 5 \\
(14 \cdot 6-31 \cdot 4)\end{array}$ & $\begin{array}{c}20 \cdot 4 \\
(12 \cdot 8-27 \cdot 6)\end{array}$ & $\begin{array}{c}20 \cdot 8 \\
(13 \cdot 2-28 \cdot 2)\end{array}$ & $\begin{array}{c}23 \cdot 2 \\
(15 \cdot 0-31 \cdot 0)\end{array}$ & $\begin{array}{c}29 \cdot 4 \\
(24 \cdot 8-34 \cdot 1)\end{array}$ & $\begin{array}{c}34 \cdot 8 \\
(24 \cdot 3-53 \cdot 3)\end{array}$ & $\begin{array}{c}36 \cdot 5 \\
(32 \cdot 0-41 \cdot 1)\end{array}$ & $\begin{array}{c}38.3 \\
(32 \cdot 7-45 \cdot 0)\end{array}$ & $\begin{array}{c}79.1 \\
(75 \cdot 7-81 \cdot 7)\end{array}$ \\
\hline Western Africa & $\begin{array}{c}8.5 \\
(4 \cdot 9-13 \cdot 0)\end{array}$ & $\begin{array}{c}10 \cdot 9 \\
(6 \cdot 3-17 \cdot 3)\end{array}$ & $\begin{array}{c}9 \cdot 4 \\
(5 \cdot 5-14 \cdot 4)\end{array}$ & $\begin{array}{c}17 \cdot 3 \\
(9 \cdot 7-28 \cdot 1)\end{array}$ & $\begin{array}{c}8 \cdot 7 \\
(5 \cdot 0-13 \cdot 2)\end{array}$ & $\begin{array}{c}10 \cdot 8 \\
(6 \cdot 1-16 \cdot 7)\end{array}$ & $\begin{array}{c}13 \cdot 5 \\
(7 \cdot 1-22 \cdot 2)\end{array}$ & $\begin{array}{c}17 \cdot 5 \\
(13 \cdot 4-23 \cdot 1)\end{array}$ & $\begin{array}{c}26 \cdot 2 \\
(15 \cdot 2-40 \cdot 3)\end{array}$ & $\begin{array}{c}28 \cdot 1 \\
(22 \cdot 8-34 \cdot 3)\end{array}$ & $\begin{array}{c}31 \cdot 8 \\
(26 \cdot 4-38 \cdot 1)\end{array}$ & $\begin{array}{c}82.0 \\
(78.1-85 \cdot 0)\end{array}$ \\
\hline Northern Africa & $\begin{array}{c}30 \cdot 3 \\
(18 \cdot 5-41 \cdot 6)\end{array}$ & $\begin{array}{c}33 \cdot 9 \\
(20 \cdot 3-46 \cdot 1)\end{array}$ & $\begin{array}{c}32 \cdot 9 \\
(19 \cdot 9-45 \cdot 1)\end{array}$ & $\begin{array}{c}34 \cdot 8 \\
(20 \cdot 6-47 \cdot 7)\end{array}$ & $\begin{array}{c}32 \cdot 0 \\
(19 \cdot 5-44 \cdot 0)\end{array}$ & $\begin{array}{c}30 \cdot 9 \\
(18 \cdot 8-42 \cdot 5)\end{array}$ & $\begin{array}{c}33 \cdot 3 \\
(20 \cdot 1-46 \cdot 7)\end{array}$ & $\begin{array}{c}47 \cdot 0 \\
(42 \cdot 0-51 \cdot 9)\end{array}$ & $\begin{array}{c}45 \cdot 4 \\
(26 \cdot 8-62 \cdot 2)\end{array}$ & $\begin{array}{c}51 \cdot 8 \\
(47 \cdot 7-56 \cdot 1)\end{array}$ & $\begin{array}{c}50 \cdot 3 \\
(42 \cdot 2-58 \cdot 0)\end{array}$ & $\begin{array}{c}79 \cdot 2 \\
(77 \cdot 3-81 \cdot 3)\end{array}$ \\
\hline Asia & $\begin{array}{c}39 \cdot 6 \\
(35 \cdot 1-43 \cdot 6)\end{array}$ & $\begin{array}{c}45 \cdot 8 \\
(40 \cdot 8-50 \cdot 8)\end{array}$ & $\begin{array}{c}41 \cdot 6 \\
(36 \cdot 7-45 \cdot 6)\end{array}$ & $\begin{array}{c}45 \cdot 2 \\
(40 \cdot 5-50 \cdot 4)\end{array}$ & $\begin{array}{c}41 \cdot 8 \\
(37 \cdot 1-46 \cdot 4)\end{array}$ & $\begin{array}{c}40 \cdot 6 \\
(36 \cdot 1-44 \cdot 8)\end{array}$ & $\begin{array}{c}43 \cdot 4 \\
(38 \cdot 0-48 \cdot 1)\end{array}$ & $\begin{array}{c}46 \cdot 9 \\
(42 \cdot 3-50 \cdot 9)\end{array}$ & $\begin{array}{c}59 \cdot 8 \\
(53 \cdot 9-66 \cdot 3)\end{array}$ & $\begin{array}{c}51 \cdot 9 \\
(47 \cdot 1-56 \cdot 4)\end{array}$ & $\begin{array}{c}56 \cdot 4 \\
(53 \cdot 2-59 \cdot 3)\end{array}$ & $\begin{array}{c}80 \cdot 1 \\
(78 \cdot 9-81 \cdot 2)\end{array}$ \\
\hline Eastern Asia & $\begin{array}{c}53 \cdot 8 \\
(46 \cdot 5-59 \cdot 4)\end{array}$ & $\begin{array}{c}61 \cdot 3 \\
(51 \cdot 4-72 \cdot 3)\end{array}$ & $\begin{array}{c}55 \cdot 2 \\
(47 \cdot 4-60 \cdot 5)\end{array}$ & $\begin{array}{c}55 \cdot 7 \\
(49 \cdot 6-60 \cdot 6)\end{array}$ & $\begin{array}{c}55 \cdot 7 \\
(49 \cdot 2-61 \cdot 3)\end{array}$ & $\begin{array}{c}54 \cdot 3 \\
(47 \cdot 3-59 \cdot 8)\end{array}$ & $\begin{array}{c}57 \cdot 0 \\
(48 \cdot 7-65 \cdot 8)\end{array}$ & $\begin{array}{c}59 \cdot 5 \\
(49 \cdot 0-70 \cdot 8)\end{array}$ & $\begin{array}{c}67 \cdot 9 \\
(57 \cdot 5-77 \cdot 2)\end{array}$ & $\begin{array}{c}63 \cdot 0 \\
(52 \cdot 3-73 \cdot 9)\end{array}$ & $\begin{array}{c}65 \cdot 6 \\
(61 \cdot 1-69 \cdot 1)\end{array}$ & $\begin{array}{c}79 \cdot 4 \\
(77 \cdot 5-81 \cdot 3)\end{array}$ \\
\hline $\begin{array}{l}\text { South-Central } \\
\text { Asia }\end{array}$ & $\begin{array}{c}31 \cdot 3 \\
(23 \cdot 2-39 \cdot 8)\end{array}$ & $\begin{array}{c}38 \cdot 0 \\
(28 \cdot 3-46 \cdot 4)\end{array}$ & $\begin{array}{c}33 \cdot 7 \\
(25 \cdot 0-42 \cdot 1)\end{array}$ & $\begin{array}{c}40 \cdot 2 \\
(30 \cdot 7-50 \cdot 7)\end{array}$ & $\begin{array}{c}34 \cdot 3 \\
(25 \cdot 5-44 \cdot 0)\end{array}$ & $\begin{array}{c}32 \cdot 6 \\
(24 \cdot 4-41 \cdot 3)\end{array}$ & $\begin{array}{c}34 \cdot 8 \\
(25 \cdot 9-43 \cdot 9)\end{array}$ & $\begin{array}{c}38 \cdot 8 \\
(31 \cdot 5-49 \cdot 1)\end{array}$ & $\begin{array}{c}58 \cdot 4 \\
(46 \cdot 1-69 \cdot 4)\end{array}$ & $\begin{array}{c}43 \cdot 5 \\
(36 \cdot 7-52 \cdot 2)\end{array}$ & $\begin{array}{c}51 \cdot 5 \\
(45 \cdot 5-57 \cdot 7)\end{array}$ & $\begin{array}{c}80 \cdot 5 \\
(79 \cdot 2-81 \cdot 9)\end{array}$ \\
\hline $\begin{array}{l}\text { South-Eastern } \\
\text { Asia }\end{array}$ & $\begin{array}{c}28 \cdot 8 \\
(22 \cdot 2-35 \cdot 5)\end{array}$ & $\begin{array}{c}33 \cdot 6 \\
(25 \cdot 2-43 \cdot 1)\end{array}$ & $\begin{array}{c}30 \cdot 7 \\
(23 \cdot 6-38 \cdot 0)\end{array}$ & $\begin{array}{c}34 \cdot 0 \\
(26 \cdot 7-41 \cdot 9)\end{array}$ & $\begin{array}{c}30 \cdot 0 \\
(23 \cdot 1-37 \cdot 0)\end{array}$ & $\begin{array}{c}30 \cdot 1 \\
(23 \cdot 2-37 \cdot 1)\end{array}$ & $\begin{array}{c}34 \cdot 7 \\
(26 \cdot 3-43 \cdot 9)\end{array}$ & $\begin{array}{c}39 \cdot 0 \\
(33 \cdot 9-44 \cdot 1)\end{array}$ & $\begin{array}{c}46 \cdot 9 \\
(35 \cdot 6-58 \cdot 8)\end{array}$ & $\begin{array}{c}47 \cdot 2 \\
(42 \cdot 8-51 \cdot 8)\end{array}$ & $\begin{array}{c}48 \cdot 4 \\
(43 \cdot 3-53 \cdot 8)\end{array}$ & $\begin{array}{c}79 \cdot 3 \\
(77 \cdot 5-81 \cdot 2)\end{array}$ \\
\hline Western Asia & $\begin{array}{c}56 \cdot 7 \\
(51 \cdot 9-60 \cdot 7)\end{array}$ & $\begin{array}{c}58 \cdot 7 \\
(53 \cdot 0-63 \cdot 4)\end{array}$ & $\begin{array}{c}58 \cdot 5 \\
(53 \cdot 1-62 \cdot 9)\end{array}$ & $\begin{array}{c}58 \cdot 3 \\
(53 \cdot 4-62 \cdot 8)\end{array}$ & $\begin{array}{c}57 \cdot 8 \\
(52 \cdot 9-62 \cdot 1)\end{array}$ & $\begin{array}{c}56 \cdot 9 \\
(52 \cdot 1-61 \cdot 0)\end{array}$ & $\begin{array}{c}60 \cdot 5 \\
(54 \cdot 8-64 \cdot 9)\end{array}$ & $\begin{array}{c}63 \cdot 8 \\
(60 \cdot 7-66 \cdot 5)\end{array}$ & $\begin{array}{c}64 \cdot 5 \\
(57 \cdot 6-70 \cdot 5)\end{array}$ & $\begin{array}{c}68 \cdot 8 \\
(66 \cdot 3-71 \cdot 3)\end{array}$ & $\begin{array}{c}67 \cdot 1 \\
(63 \cdot 9-70 \cdot 1)\end{array}$ & $\begin{array}{c}81 \cdot 4 \\
(79 \cdot 9-82 \cdot 9)\end{array}$ \\
\hline Europe & $\begin{array}{c}74 \cdot 3 \\
(71 \cdot 9-76 \cdot 4)\end{array}$ & $\begin{array}{c}75 \cdot 4 \\
(72 \cdot 9-77 \cdot 5)\end{array}$ & $\begin{array}{c}75 \cdot 2 \\
(72 \cdot 6-77 \cdot 4)\end{array}$ & $\begin{array}{c}74 \cdot 9 \\
(72 \cdot 7-76 \cdot 9)\end{array}$ & $\begin{array}{c}75 \cdot 0 \\
(72 \cdot 8-77 \cdot 0)\end{array}$ & $\begin{array}{c}74 \cdot 4 \\
(72 \cdot 0-76 \cdot 4)\end{array}$ & $\begin{array}{c}75 \cdot 2 \\
(72 \cdot 7-77 \cdot 5)\end{array}$ & $\begin{array}{c}76 \cdot 6 \\
(74 \cdot 8-78 \cdot 3)\end{array}$ & $\begin{array}{c}77 \cdot 9 \\
(75 \cdot 4-80 \cdot 1)\end{array}$ & $\begin{array}{c}77 \cdot 8 \\
(76 \cdot 0-79 \cdot 3)\end{array}$ & $\begin{array}{c}77 \cdot 9 \\
(76 \cdot 3-79 \cdot 4)\end{array}$ & $\begin{array}{c}82 \cdot 2 \\
(81 \cdot 0-83 \cdot 3)\end{array}$ \\
\hline Eastern Europe & $\begin{array}{c}65 \cdot 7 \\
(59 \cdot 9-70 \cdot 3)\end{array}$ & $\begin{array}{c}67 \cdot 4 \\
(61 \cdot 4-72 \cdot 5)\end{array}$ & $\begin{array}{c}67 \cdot 5 \\
(61 \cdot 1-72 \cdot 6)\end{array}$ & $\begin{array}{c}66 \cdot 9 \\
(61 \cdot 6-71 \cdot 5)\end{array}$ & $\begin{array}{c}67 \cdot 1 \\
(61 \cdot 6-71 \cdot 7)\end{array}$ & $\begin{array}{c}65 \cdot 9 \\
(60 \cdot 2-70 \cdot 4)\end{array}$ & $\begin{array}{c}67 \cdot 4 \\
(60 \cdot 7-72 \cdot 1)\end{array}$ & $\begin{array}{c}70 \cdot 4 \\
(66 \cdot 5-74 \cdot 3)\end{array}$ & $\begin{array}{c}72 \cdot 4 \\
(66 \cdot 5-77 \cdot 8)\end{array}$ & $\begin{array}{c}72 \cdot 6 \\
(69 \cdot 1-76 \cdot 3)\end{array}$ & $\begin{array}{c}72 \cdot 7 \\
(69 \cdot 2-75 \cdot 9)\end{array}$ & $\begin{array}{c}81 \cdot 3 \\
(79 \cdot 5-83 \cdot 3)\end{array}$ \\
\hline Northern & $80 \cdot 6$ & $81 \cdot 1$ & $80 \cdot 8$ & $80 \cdot 7$ & $80 \cdot 8$ & $80 \cdot 6$ & $80 \cdot 8$ & $81 \cdot 0$ & 81.8 & $81 \cdot 2$ & $81 \cdot 5$ & $82 \cdot 5$ \\
\hline Europe & $(78 \cdot 3-82 \cdot 7)$ & (78.9-83.3) & $(78 \cdot 5-82 \cdot 9)$ & $(78 \cdot 6-82 \cdot 8)$ & (78.6-82.9) & $(78 \cdot 3-82 \cdot 7)$ & $(78.5-82 \cdot 9)$ & $(78 \cdot 7-83 \cdot 1)$ & $(79 \cdot 7-83 \cdot 8)$ & $(79 \cdot 0-83 \cdot 4)$ & $(79 \cdot 5-83 \cdot 5)$ & $(80 \cdot 4-84.6)$ \\
\hline $\begin{array}{l}\text { Southern } \\
\text { Europe }\end{array}$ & $\begin{array}{c}76 \cdot 2 \\
(73 \cdot 9-78 \cdot 7)\end{array}$ & $\begin{array}{c}77 \cdot 3 \\
(74 \cdot 9-79 \cdot 8)\end{array}$ & $\begin{array}{c}76 \cdot 9 \\
(74 \cdot 4-79.5)\end{array}$ & $\begin{array}{c}76 \cdot 5 \\
(74 \cdot 3-79 \cdot 0)\end{array}$ & $\begin{array}{c}76 \cdot 6 \\
(74 \cdot 3-79 \cdot 1)\end{array}$ & $\begin{array}{c}76 \cdot 3 \\
(74 \cdot 0-78 \cdot 7)\end{array}$ & $\begin{array}{c}77 \cdot 2 \\
(74 \cdot 7-79 \cdot 8)\end{array}$ & $\begin{array}{c}78 \cdot 3 \\
(76 \cdot 2-80 \cdot 4)\end{array}$ & $\begin{array}{c}78 \cdot 8 \\
(76 \cdot 3-81 \cdot 5)\end{array}$ & $\begin{array}{c}79 \cdot 4 \\
(77 \cdot 2-81 \cdot 5)\end{array}$ & $\begin{array}{c}79 \cdot 1 \\
(77 \cdot 2-81 \cdot 2)\end{array}$ & $\begin{array}{c}82 \cdot 3 \\
(80 \cdot 4-84 \cdot 3)\end{array}$ \\
\hline
\end{tabular}




\begin{tabular}{|c|c|c|c|c|c|c|c|c|c|c|c|c|}
\hline Western Eu & $\begin{array}{c}81 \cdot 6 \\
(79 \cdot 4-83 \cdot 6)\end{array}$ & $\begin{array}{c}82 \cdot 2 \\
(80 \cdot 0-84 \cdot 1)\end{array}$ & $\begin{array}{c}81 \cdot 6 \\
(79 \cdot 5-83 \cdot 6)\end{array}$ & $\begin{array}{c}81 \cdot 8 \\
(79 \cdot 8-83 \cdot 7)\end{array}$ & $\begin{array}{c}81 \cdot 8 \\
(79 \cdot 8-83 \cdot 8)\end{array}$ & $\begin{array}{c}81 \cdot 6 \\
(79 \cdot 4-83 \cdot 6)\end{array}$ & $\begin{array}{c}81 \cdot 8 \\
(79 \cdot 7-83 \cdot 8)\end{array}$ & $\begin{array}{c}81 \cdot 7 \\
(79 \cdot 5-83 \cdot 7)\end{array}$ & $\begin{array}{c}82 \cdot 7 \\
(80 \cdot 9-84 \cdot 5)\end{array}$ & $\begin{array}{c}82 \cdot 0 \\
(79 \cdot 9-83 \cdot 9)\end{array}$ & $\begin{array}{c}82 \cdot 3 \\
(80 \cdot 5-84 \cdot 1)\end{array}$ & $\begin{array}{c}83 \cdot 2 \\
(81 \cdot 6-84 \cdot 7)\end{array}$ \\
\hline $\begin{array}{l}\text { Latin America/ } \\
\text { Caribbean }\end{array}$ & $\begin{array}{c}55 \cdot 0 \\
(51 \cdot 2-58 \cdot 7)\end{array}$ & $\begin{array}{c}60 \cdot 6 \\
(56 \cdot 2-65 \cdot 3)\end{array}$ & $\begin{array}{c}55 \cdot 9 \\
(52 \cdot 3-59 \cdot 5)\end{array}$ & $\begin{array}{c}57 \cdot 8 \\
(54 \cdot 3-60 \cdot 7)\end{array}$ & $\begin{array}{c}57 \cdot 8 \\
(54 \cdot 3-61 \cdot 4)\end{array}$ & $\begin{array}{c}55 \cdot 6 \\
(51 \cdot 8-59 \cdot 3)\end{array}$ & $\begin{array}{c}58 \cdot 2 \\
(53 \cdot 8-62 \cdot 6)\end{array}$ & $\begin{array}{c}61 \cdot 2 \\
(57 \cdot 0-65 \cdot 6)\end{array}$ & $\begin{array}{c}68 \cdot 4 \\
(63 \cdot 9-72 \cdot 7)\end{array}$ & $\begin{array}{c}64 \cdot 8 \\
(60 \cdot 1-69 \cdot 7)\end{array}$ & $\begin{array}{c}66 \cdot 9 \\
(64 \cdot 6-69 \cdot 3)\end{array}$ & $\begin{array}{c}81.0 \\
(79.5-82.5)\end{array}$ \\
\hline Caribbean & $\begin{array}{c}45 \cdot 0 \\
(36 \cdot 3-54 \cdot 1)\end{array}$ & $\begin{array}{c}46 \cdot 4 \\
(37 \cdot 5-56 \cdot 1)\end{array}$ & $\begin{array}{c}47 \cdot 2 \\
(37 \cdot 5-58 \cdot 1)\end{array}$ & $\begin{array}{c}48 \cdot 7 \\
(38 \cdot 6-59 \cdot 4)\end{array}$ & $\begin{array}{c}46 \cdot 7 \\
(37 \cdot 7-56 \cdot 5)\end{array}$ & $\begin{array}{c}45 \cdot 4 \\
(36 \cdot 7-55 \cdot 0)\end{array}$ & $\begin{array}{c}48.9 \\
(38.8-57 \cdot 8)\end{array}$ & $\begin{array}{c}53 \cdot 4 \\
(46 \cdot 5-59 \cdot 4)\end{array}$ & $\begin{array}{c}56 \cdot 3 \\
(43 \cdot 5-71 \cdot 5)\end{array}$ & $\begin{array}{c}59 \cdot 3 \\
(54 \cdot 1-64 \cdot 2)\end{array}$ & $\begin{array}{c}58 \cdot 8 \\
(51 \cdot 8-66 \cdot 0)\end{array}$ & $\begin{array}{c}80 \cdot 7 \\
(77 \cdot 9-83 \cdot 3)\end{array}$ \\
\hline Central America & $\begin{array}{c}45 \cdot 4 \\
(35 \cdot 9-54 \cdot 1)\end{array}$ & $\begin{array}{c}53 \cdot 0 \\
(41 \cdot 5-62 \cdot 8)\end{array}$ & $\begin{array}{c}46 \cdot 1 \\
(36 \cdot 6-55 \cdot 2)\end{array}$ & $\begin{array}{c}51 \cdot 7 \\
(46 \cdot 4-57 \cdot 3)\end{array}$ & $\begin{array}{c}49 \cdot 9 \\
(42 \cdot 0-57 \cdot 4)\end{array}$ & $\begin{array}{c}46 \cdot 4 \\
(37 \cdot 6-54 \cdot 7)\end{array}$ & $\begin{array}{c}50 \cdot 1 \\
(40 \cdot 5-61 \cdot 1)\end{array}$ & $\begin{array}{c}50 \cdot 9 \\
(42 \cdot 5-58 \cdot 4)\end{array}$ & $\begin{array}{c}66 \cdot 8 \\
(58 \cdot 8-74 \cdot 3)\end{array}$ & $\begin{array}{c}56 \cdot 0 \\
(46 \cdot 8-65 \cdot 7)\end{array}$ & $\begin{array}{c}61 \cdot 9 \\
(56 \cdot 1-66 \cdot 8)\end{array}$ & $\begin{array}{c}81.6 \\
(79 \cdot 4-83 \cdot 5)\end{array}$ \\
\hline South America & $\begin{array}{c}60 \cdot 2 \\
(54 \cdot 8-64 \cdot 2)\end{array}$ & $\begin{array}{c}65 \cdot 3 \\
(59 \cdot 5-69 \cdot 7)\end{array}$ & $\begin{array}{c}61 \cdot 1 \\
(56 \cdot 0-65 \cdot 6)\end{array}$ & $\begin{array}{c}61 \cdot 3 \\
(56 \cdot 5-64 \cdot 8)\end{array}$ & $\begin{array}{c}62 \cdot 2 \\
(56 \cdot 9-66 \cdot 9)\end{array}$ & $\begin{array}{c}60 \cdot 5 \\
(55 \cdot 2-64 \cdot 5)\end{array}$ & $\begin{array}{c}62 \cdot 6 \\
(56 \cdot 9-67 \cdot 6)\end{array}$ & $\begin{array}{c}66 \cdot 6 \\
(61 \cdot 1-72 \cdot 5)\end{array}$ & $\begin{array}{c}70 \cdot 0 \\
(65 \cdot 2-75 \cdot 3)\end{array}$ & $\begin{array}{c}69 \cdot 3 \\
(63 \cdot 7-74 \cdot 2)\end{array}$ & $\begin{array}{c}69 \cdot 9 \\
(66 \cdot 3-72 \cdot 5)\end{array}$ & $\begin{array}{c}80 \cdot 7 \\
(79 \cdot 0-82 \cdot 6)\end{array}$ \\
\hline North America & $\begin{array}{c}83 \cdot 0 \\
(81 \cdot 6-84 \cdot 4)\end{array}$ & $\begin{array}{c}83 \cdot 8 \\
(82 \cdot 4-85 \cdot 2)\end{array}$ & $\begin{array}{c}83 \cdot 0 \\
(81 \cdot 6-84 \cdot 5)\end{array}$ & $\begin{array}{c}83 \cdot 0 \\
(81 \cdot 6-84 \cdot 5)\end{array}$ & $\begin{array}{c}83 \cdot 1 \\
(81 \cdot 7-84 \cdot 5)\end{array}$ & $\begin{array}{c}83 \cdot 0 \\
(81 \cdot 6-84 \cdot 4)\end{array}$ & $\begin{array}{c}83 \cdot 1 \\
(81 \cdot 7-84 \cdot 5)\end{array}$ & $\begin{array}{c}83.0 \\
(81 \cdot 6-84.5)\end{array}$ & $\begin{array}{c}84 \cdot 0 \\
(82 \cdot 6-85 \cdot 3)\end{array}$ & $\begin{array}{c}83 \cdot 1 \\
(81 \cdot 7-84 \cdot 5)\end{array}$ & $\begin{array}{c}83 \cdot 5 \\
(82 \cdot 2-84 \cdot 8)\end{array}$ & $\begin{array}{c}84 \cdot 1 \\
(82 \cdot 8-85 \cdot 3)\end{array}$ \\
\hline Oceania & $\begin{array}{c}64 \cdot 4 \\
(58 \cdot 9-69 \cdot 2)\end{array}$ & $\begin{array}{c}65 \cdot 3 \\
(59 \cdot 5-70 \cdot 3)\end{array}$ & $\begin{array}{c}65 \cdot 2 \\
(59 \cdot 4-70 \cdot 3)\end{array}$ & $\begin{array}{c}66 \cdot 2 \\
(60 \cdot 5-71 \cdot 3)\end{array}$ & $\begin{array}{c}65 \cdot 8 \\
(59 \cdot 9-70 \cdot 5)\end{array}$ & $\begin{array}{c}64 \cdot 7 \\
(59 \cdot 2-69 \cdot 6)\end{array}$ & $\begin{array}{c}65 \cdot 4 \\
(59 \cdot 4-70 \cdot 5)\end{array}$ & $\begin{array}{c}68 \cdot 5 \\
(64 \cdot 1-73 \cdot 2)\end{array}$ & $\begin{array}{c}70 \cdot 6 \\
(63 \cdot 6-76 \cdot 8)\end{array}$ & $\begin{array}{c}70 \cdot 4 \\
(66 \cdot 5-74 \cdot 6)\end{array}$ & $\begin{array}{c}71 \cdot 1 \\
(66 \cdot 4-75 \cdot 2)\end{array}$ & $\begin{array}{c}81 \cdot 5 \\
(78 \cdot 6-84 \cdot 5)\end{array}$ \\
\hline $\begin{array}{l}\text { Oceania } \\
\text { (Region) }\end{array}$ & $\begin{array}{c}19 \cdot 3 \\
(6 \cdot 7-33 \cdot 3)\end{array}$ & $\begin{array}{c}21 \cdot 6 \\
(7 \cdot 4-37 \cdot 1)\end{array}$ & $\begin{array}{c}22 \cdot 4 \\
(7 \cdot 9-38)\end{array}$ & $\begin{array}{c}23 \cdot 6 \\
(8 \cdot 1-40 \cdot 0)\end{array}$ & $\begin{array}{c}21 \cdot 4 \\
(7 \cdot 6-36 \cdot 6)\end{array}$ & $\begin{array}{c}20 \cdot 1 \\
(7 \cdot 1-34 \cdot 2)\end{array}$ & $\begin{array}{c}23 \cdot 0 \\
(7 \cdot 6-39 \cdot 7)\end{array}$ & $\begin{array}{c}35 \cdot 3 \\
(26 \cdot 3-45 \cdot 6)\end{array}$ & $\begin{array}{c}35 \cdot 4 \\
(11 \cdot 7-58 \cdot 2)\end{array}$ & $\begin{array}{c}42 \cdot 1 \\
(33 \cdot 2-51 \cdot 7)\end{array}$ & $\begin{array}{c}41 \cdot 2 \\
(29 \cdot 5-53 \cdot 1)\end{array}$ & $\begin{array}{c}78 \cdot 2 \\
(72 \cdot 5-83 \cdot 7)\end{array}$ \\
\hline $\begin{array}{l}\text { Australia/New } \\
\text { Zealand }\end{array}$ & $\begin{array}{c}79 \cdot 1 \\
(74 \cdot 8-83 \cdot 4)\end{array}$ & $\begin{array}{c}79 \cdot 6 \\
(75 \cdot 3-83 \cdot 7)\end{array}$ & $\begin{array}{c}79 \cdot 2 \\
(74 \cdot 9-83 \cdot 4)\end{array}$ & $\begin{array}{c}80 \cdot 1 \\
(76 \cdot 4-83 \cdot 9)\end{array}$ & $\begin{array}{c}80 \cdot 3 \\
(76 \cdot 2-84 \cdot 4)\end{array}$ & $\begin{array}{c}79 \cdot 3 \\
(75 \cdot 0-83 \cdot 7)\end{array}$ & $\begin{array}{c}79 \cdot 3 \\
(75 \cdot 2-83 \cdot 6)\end{array}$ & $\begin{array}{c}79 \cdot 4 \\
(75 \cdot 3-83 \cdot 7)\end{array}$ & $\begin{array}{c}82 \cdot 1 \\
(78 \cdot 5-85 \cdot 6)\end{array}$ & $\begin{array}{c}79 \cdot 6 \\
(75 \cdot 6-83 \cdot 8)\end{array}$ & $\begin{array}{c}80 \cdot 9 \\
(77 \cdot 3-84 \cdot 5)\end{array}$ & $\begin{array}{c}82 \cdot 6 \\
(79 \cdot 7-85 \cdot 8)\end{array}$ \\
\hline
\end{tabular}

* Policy interventions are defined in Table 2

+ Comprehensive 50\%/100\%: Expand treatment access and improve service delivery to close the gap with mean of HIC by 50\%/100\% 